\title{
EFECTO DE DIFERENTES TIEMPOS DE ALMACENAMIENTO, DESINFECTANTES Y EXTRACTOS VEGETALES EN POSCOSECHA SOBRE TUBERCULOS DE ÑAME BLANCO (Dioscorea alata L.) DE EXPORTACIÓN ${ }^{1}$
}

\author{
Ligia Mayela López Marín
}

RESUMEN

\begin{abstract}
Se evaluó el efecto de diferentes tiempos de almacenamiento, desinfectantes y fungicidas orgánicos e inorgánicos, sobre la apariencia externa, incidencia y severidad de enfermedades poscosecha de tubérculos de ñame blanco (Dioscorea alata) de exportación. Se probaron cuatro tiempos de almacenamiento $(7,14,21$ y 28 días) y siete tratamientos desinfectantes: 1 . $\mathrm{NaOCl}$ (Hipoclorito de sodio a $150 \mathrm{mg} / \mathrm{I}$ i.a.); 2. Extracto de semillas de cítricos (Kilol a $750 \mathrm{mg} /$ I i.a.); 3. Extracto biogénico de semillas de cítricos (Biocto a 5.000,00 mg/ I P.C.) + Profilm 600 $40 \mathrm{SL}$ adherente, dispersante, penetrante $2.000 \mathrm{mg} / \mathrm{I}$ P.C.); 4. Peróxido de hidrógeno ( $\mathrm{H}_{2} \mathrm{O} 2$ a 10.000,00 mg/ I); 5. Citrato de plata (Bacsan 0,24 SL 10,00 mg / I i.a.); 6. Testigo relativo (lavado con agua). 7. Citrato de plata (Bacsan 0,24 SL 5,00 mg/ I i.a.), aplicados por inmersión durante 3 minutos. Todos los tubérculos fueron secados y almacenados en cajas de cartón de $23,00 \mathrm{~kg}$, en cámara fría a $16{ }^{\circ} \mathrm{C} \pm 2{ }^{\circ} \mathrm{C}$ con $90 \% \mathrm{H}$.R. Se empleó un diseño irrestricto al azar con un arreglo bifactorial, con tres repeticiones. Las variables evaluadas fueron apariencia externa (apariencia del corte, micelio en el corte, brotes, yemas y micelio en daño mecánico), incidencia, severidad e identificación de microorganismos asociados a lesiones presentes en los tubérculos. Los tubérculos almacenados por 7 días y 0 días anaquel presentaron la mejor apariencia del corte, así como la menor presencia de micelio en el corte. Tubérculos tratados con hipoclorito de sodio y con 7 días anaquel, presentaron menor presencia de micelio en el corte. A 0 (cero) y 14 días anaquel, todos los desinfectantes fueron similares al Testigo en la presencia de micelio en el corte con excepción del Bacsan $5 \mathrm{mg} / \mathrm{l}$. Los brotes y yemas de tubérculos evaluados no presentaron diferencias significativas. A 7 y 14 días anaquel, hubo diferencias significativas entre los desinfectantes aplicados para la variable incidencia de enfermedades y fue debido al Bacsan $5 \mathrm{mg} / \mathrm{I}$. A 0, 7 y 14 días anaquel, Bacsan $5 \mathrm{mg} / \mathrm{I}$ obtuvo el mayor número de lesiones presentes en tubérculos de ñame y fue diferente a todos los demás desinfectantes evaluados. Los hongos presentes en el corte, daño mecánico y lesiones de enfermedades fueron Penicillium spp. (85,70\%) y Aspergillus spp. (7,14\%). No se presentaron enfermedades bacteriales en los tubérculos analizados.
\end{abstract}

Palabras claves: ñame blanco (Dioscorea alata L.), tiempos de almacenamiento, desinfectantes, apariencia externa, incidencia, severidad, anaquel.

\footnotetext{
${ }^{1}$ Financiado por el Instituto Nacional de Innovación y Transferencia en Tecnología Agropecuaria (INTA), Costa Rica.

${ }^{2}$ Instituto de Innovación y Transferencia de Tecnología Agropecuaria (INTA), Costa Rica. Teléfono: (506)2231-2344 ext. 411. Telefax: (506)2232-1949; Correo electrónico: llopez@ inta.go.cr.

${ }^{3}$ Luis Quirós. Exportadora de Tubérculos de Costa Rica, La Rita de Guápiles, Costa Rica. Teléfono: (506)2763-4289 Telefax: (506)2763-3494.
} 


\section{INTRODUCCIÓN}

Las nuevas tendencias de apertura comercial de Costa Rica brindan oportunidades para la comercialización de productos agrícolas con países de Centroamérica, el Caribe, Estados Unidos, así como también, con otros países de Europa y Asia.

Los tubérculos del ñame son una fuente importante de carbohidratos para las poblaciones de África Tropical y Subtropical, Centroamérica y Sur América, parte de Asia e islas del Caribe y del Pacífico y el consumo anual a nivel mundial supera los 30 millones de toneladas de ñame, siendo Nigeria el mayor productor del mundo con 22 millones de toneladas por año (FAO, 1998 citado por Amusa et al., 2003; Adelusi y Lawanson 1987; Coursey 1967).

De acuerdo con el Banco Central de Costa Rica, en el 2006, Costa Rica pasó de producir 5.540 toneladas de ñame a 15.461,59 toneladas en el año 2009. Durante el período 2009, Costa Rica exportó ñame, lo que generó \$13 621.215, a países como Puerto Rico, Estados Unidos, Martinica, Guadalupe y otros países como Canadá, Reino Unido, Holanda, Honduras, España, Colombia, Panamá y algunas Islas del Caribe (CNP 2010).

Aún cuando la producción de ñame representa una fuente de ingresos para los pequeños y medianos agricultores, la actividad se ve restringida porque el sector es poco organizado, las prácticas de producción son deficientes y consecuentemente, se afecta la calidad del producto. Adicionalmente, es común que se presenten pérdidas de importancia, ocasionadas por falta de prácticas de manejo poscosecha adecuadas (Herrera, Umaña 1994 citados por Segura 2000).

Onayemi (1983) informado por Amusa et al. (2003), mencionó que las pérdidas en Nigeria superan el $50 \%$ de los ñames cosechados y almacenados. Así mismo, las principales causas de pérdidas poscosecha son las lesiones provocadas por nematodos, golpes y daños mecánicos que afectan la apariencia externa y favorecen la entrada de hongos y bacterias que finalmente, le causan pudriciones a los tubérculos (Murse et al. 2000 citado por Amusa et al. 2003; FAO 1993).

Amusa et al. (2003) indicaron que los agentes que causan enfermedades en ñame no sólo reducen la cantidad de ñames producidos, sino que reducen la calidad del producto. Estas enfermedades aparecen en el campo, en cosecha y después de la cosecha. Aunado a lo anterior, los autores encontraron microorganismos asociados con el almacenamiento y mercadeo de tubérculos de ñame dentro de los cuales están: Botryodiplodia theobromae, Aspergillus tamari, Penicillium oxalcum, P. cyplopium, $P$. italicum, Fusarium oxysporum, F. solani, Rhizopus nigricans, Sclerotium rolfsii, Mucor circineloides, Trichoderma viridae y Erwinia carotovora.

Eyensu y Coursey (1992) citados por Okigbo (2004), mencionaron que los géneros de hongos que aparecen con frecuencia asociados a pérdidas en almacenamiento en ñame fueron Botriodiplodia, Fusarium, Penicillium, Rosellinia, Aspergillus, Hendersonula, Macrophomina, Rhizopus, Cladosporium, Geotrichum y una bacteria del género Serratia.

En las empacadoras de ñame, la finalidad de realizar el lavado, es para eliminar las cargas de bacterias, hongos y restos de suciedad. Además, el agua es necesaria para la preparación de soluciones tales como ceras, fungicidas, antitranspirantes y abrillantadores, que son normalmente empleados para mejorar la apariencia y la conservación del producto (CNP 2001). Kornoski et al. (2006) mencionan que el lavado es un paso importante en la línea de empaque y es donde se realiza el primer tratamiento con desinfectantes o fungicidas, cuya finalidad es desinfectar la superficie del fruto.

La mayoría de los patógenos que infectan los tubérculos de ñame provienen de campo, no 
obstante, es frecuente que se observen durante el período de almacenamiento causando pérdidas. Es común encontrar tubérculos de ñame con pérdidas de 10 a $20 \%$ durante los primeros 3 (tres) meses de almacenamiento, aunque después de 6 (seis) meses las pérdidas pueden incrementarse entre el 50 al $60 \%$ (Ikotun 1986 citado por Okigbo 2004; Jones1985 citado por Okigbo 2004; Nnodu y Nwankiti 1986 citados por Okigbo 2004; Ogali et al. (1991) citados por Okigbo (2004).

Es evidente que las pérdidas poscosecha que se presentan por enfermedades en raíces y tubérculos son de difícil combate, debido a que en la mayoría de los casos, no se cuenta con fungicidas aprobados por E.P.A. (Agencia de Protección Ambiental, Estados Unidos), lo que dificulta el control químico para reducir enfermedades poscosecha y por ende, se dificulta mejorar la calidad del producto exportable (FAO 1993).

Algunos químicos se han aplicado para reducir enfermedades poscosecha en ñame, sin embargo, es necesaria la búsqueda de otras alternativas diferentes a los agroquímicos, dado que son fuertemente regulados en la aprobación de los registros y en el uso para cada país (Okigbo 2003 citado por Okigbo 2004; Okigbo 2001 citado por Okigbo 2004; Garrett 1972 citado por Okigbo 2004).

El objetivo de esta investigación fue probar diferentes tiempos de almacenamiento, desinfectantes y fungicidas orgánicos e inorgánicos sobre la apariencia externa, incidencia y severidad de enfermedades poscosecha de tubérculos de ñame blanco (Dioscorea alata) de exportación.

\section{MATERIALES Y METODOS}

\section{Evaluación de desinfectantes y extractos vegetales}

La investigación se llevó a cabo de setiembre a noviembre del año 2007, en el Laboratorio de Tecnología Poscosecha de la Universidad de Costa Rica, San Pedro de Montes de
Oca, San José. Se emplearon tubérculos de ñame (Dioscorea alata) procedentes de la planta empacadora - exportadora de raíces y tubérculos de Luis Quirós en La Rita, Jiménez de Guápiles, provincia de Limón, Costa Rica.

Se evaluaron desinfectantes y extractos vegetales como tratamientos poscosecha para el combate de enfermedades de tubérculos de ñame de calidad de exportación, según norma de calidad (Saborío, 2003) Los tubérculos empleados se estibaron por 5 (cinco) días, según se hace comercialmente, dentro de la empacadora, de manera que permitiera el secado, la cicatrización de heridas que ocurrieron durante la cosecha, trasiego del producto a la empacadora y durante la acción del lavado del mismo. El procedimiento permitió reforzar las zonas de la piel suberosa que sufrieron daños por la manipulación (FAO 1993).

Los tubérculos de ñame se trasladaron en cajas de cartón de 23,00 kg hasta el Laboratorio de Poscosecha y se colocaron en cajas plásticas con ranuras para facilitar la aplicación de los productos desinfectantes por inmersión, durante 3 (tres) minutos; seguidamente, se escurrieron y se colocaron en mesas forradas de papel Kraft (parafinado), para secar los tubérculos con la ayuda de ventiladores de pie, por un período de 14 horas.

Los tratamientos evaluados en el ensayo fueron los siguientes: 1. $\mathrm{NaOCl}$ (Hipoclorito de sodio 150,00 mg/ I i.a.; 2. Extracto de semillas de cítricos (Kilol 750,00 mg/ I i.a.; 3. Extracto biogénico de semillas de cítricos (Biocto $5.000,00$ mg/ I P.C.) + Profilm $60040 \mathrm{SL}$ (2.000,00 mg/ I P.C. de adherente, dispersante y penetrante); 4. Peróxido de hidrógeno $\left(\mathrm{H}_{2} \mathrm{O}_{2}\right)$ $10.000,00 \mathrm{mg} / \mathrm{I} ; 5$. Citrato de plata (Bacsan 0,24 SL 10,00 mg/ I i.a.); 6. Testigo relativo (lavado con agua). 7. Citrato de plata (Bacsan 0,24 SL 5,00 mg/ I i.a.).

Los tubérculos de ñame se revisaron de manera independiente para verificar su calidad, se envolvieron en papel periódico y se colocaron en cajas de cartón de 23,00 
$\mathrm{kg}$. Seguidamente, las cajas se almacenaron aleatoriamente en una cámara fría graduada a $16{ }^{\circ} \mathrm{C} \pm 2{ }^{\circ} \mathrm{C}$ con una humedad relativa de $90 \%$.

El ensayo se dispuso en un diseño irrestricto al azar con un arreglo bifactorial, donde el factor uno correspondió a cuatro tiempos de almacenamiento $(7,14,21$ y 28 días) y el factor dos correspondió a siete tratamientos desinfectantes. En cada tratamiento se usaron tres repeticiones y se realizaron tres evaluaciones en el tiempo. Cada repetición consistió de una caja de $23,00 \mathrm{~kg}$ de producto y de cada repetición se evaluaron al azar cinco tubérculos por semana. La unidad muestral correspondió a un tubérculo de ñame. Se empleó un análisis de ANDEVA y una prueba de comparación de medias de Tukey $(p \leq 0,05)$. Los tubérculos de ñame aplicados con los diferentes desinfectantes se almacenaron en cámara fría durante 7, 14, 21 y 28 días, simulando el tiempo de transporte que tardaría el producto al ser exportado a diferentes mercados internacionales. Concluido el período de almacenamiento, los tubérculos se sacaron de la cámara fría y se evaluaron a los 0, 7 y 14 días, simulando el tiempo en anaquel.

Cada 7 días se evaluaron cinco tubérculos por repetición por tratamiento de las cajas dispuestas en la cámara fría y en anaquel y se consideraron las siguientes variables:

A. Apariencia externa: apariencia del corte (unión con la planta), micelio presente en el corte, brotes, yemas y presencia de micelio en daño mecánico. Esta evaluación se hizo con base en la siguiente escala de deterioro de la apariencia externa: Grado 1: $0 \%$ deterioro de la apariencia externa; Grado 2: mayor que 0 y hasta $25 \%$; Grado 3: mayor que $25 \%$ y hasta $50 \%$; Grado 4: mayor que $50 \%$ y hasta $75 \%$; Grado 5: mayor que $75 \%$ a $100 \%$.

B. Incidencia (presencia de tubérculos enfermos) y severidad (número de lesiones causadas por diversas enfermedades en los tubérculos).
C. Identificación de microorganismos asociados con las lesiones presentes en los tubérculos. Este análisis se realizó en el Laboratorio de Fitoprotección del Instituto de Innovación y Transferencia de Tecnología Agropecuaria (INTA), del Ministerio de Agricultura y Ganadería.

\section{RESULTADOS Y DISCUSIÓN}

Los resultados del ensayo se desglosaron de acuerdo a las tres evaluaciones realizadas a tubérculos de ñame de exportación aplicados con diferentes desinfectantes poscosecha y colocados bajo diferentes tiempos de almacenamiento: primera evaluación (salida de cámara fría a $16{ }^{\circ} \mathrm{C}$ ), segunda evaluación (siete días después de permanecer a temperatura ambiente o simulación de anaquel) y tercera evaluación (catorce días después de permanecer a temperatura ambiente o simulación de anaquel).

Primera Evaluación. Salida de cámara (0 Días Simulación en Anaquel).

\section{A. Apariencia Externa}

\section{Apariencia del Corte (corte de unión con la planta):}

En el análisis de varianza para la variable apariencia del corte de los tubérculos evaluados a la salida de cámara fría, se presentaron diferencias altamente significativas $(p \leq 0,01)$ según Tukey en el tiempo de almacenamiento, así como en los tratamientos desinfectantes (Figuras 1 y 2). No existió dependencia entre el tiempo de almacenamiento y los desinfectantes aplicados por no presentarse diferencias estadísticas en la interacción de los mismos. 


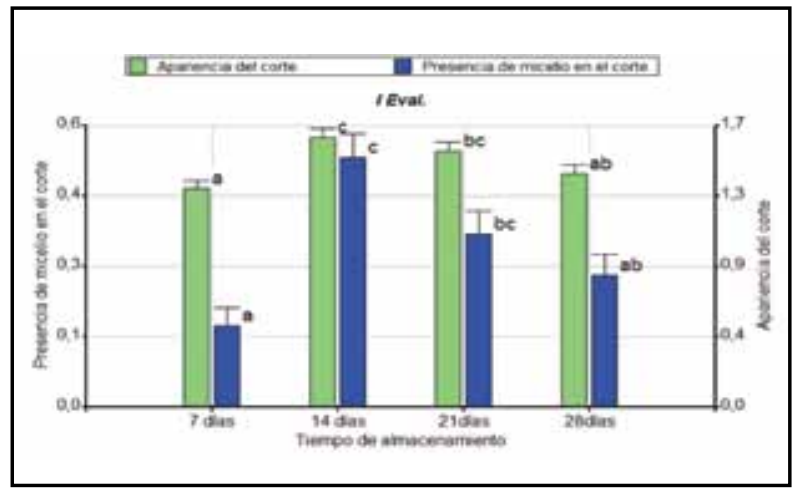

Figura 1. Apariencia del corte (unión con la planta) y presencia de micelio en tubérculos de ñame Diamantes 22, según el tiempo de almacenamiento en cámara fría a $16^{\circ} \mathrm{C}$. San José, Costa Rica. 2007.

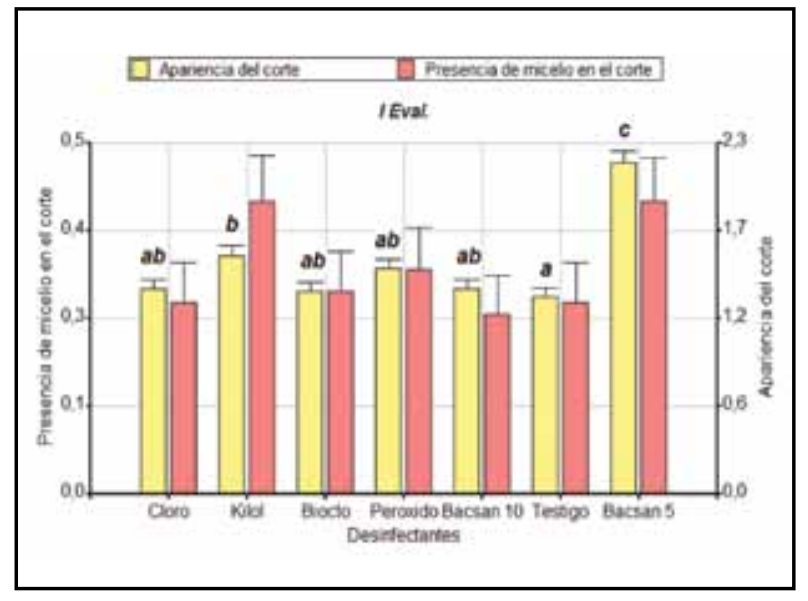

Figura 2. Apariencia del corte y presencia de micelio en el mismo corte de tubérculos de ñame Diamantes 22 después de ser tratados con desinfectantes y almacenados en cámara fría $\left(16^{\circ} \mathrm{C}\right)$ San José, Costa Rica. 2007.

Con base en la escala de deterioro de la apariencia del corte de los tubérculos evaluados a los 7, 14, 21 y 28 días de permanencia en cámara fría fue diferente (según prueba de Tukey). Los tubérculos almacenados por siete días presentaron la mejor apariencia del corte; en tanto que, aquellos almacenados durante 14 días presentaron el mayor deterioro en el corte (Figura 1), lo que se detectó comercialmente y podría deberse a la pérdida de humedad de los tubérculos ocurrida en el tiempo, lo cual hace que se arrugue y reduzca el corte.
Con respecto a los desinfectantes aplicados, se encontró que los desinfectantes utilizados fueron estadísticamente diferentes e inferiores al testigo, siendo éste último el que presentó el menor deterioro en el corte. Asimismo, el Testigo (lavado con agua) es uno de los tratamientos que se emplea en las empresas empacadoras de producto de exportación de ñame blanco. En contraposición a lo anterior, el tratamiento con Bacsan $5,00 \mathrm{mg} / \mathrm{I}$ presentó el mayor deterioro en la apariencia del corte (Figura 2). Esto pudo deberse a que las concentraciones de los tratamientos empleados no fueron las óptimas, o bien, el manejo y la selección previa de los tubérculos fueron buenos, lo que hace innecesario el empleo de desinfectantes.

\section{Presencia de micelio en el corte (corte de unión con la planta):}

En la variable presencia de micelio en el corte de los tubérculos, no hubo diferencias significativas entre los tratamientos desinfectantes aplicados, mientras que si hubo diferencias altamente significativas $(p \leq$ 0,01 ) en el tiempo de almacenamiento de los mismos. Por otro lado, no existió dependencia entre el tiempo de almacenamiento y los desinfectantes aplicados por no presentarse diferencias estadísticas en la interacción de los mismos (Figura 1 y 2).

Los tubérculos almacenados durante 7 (siete) días, presentaron la menor presencia de micelio (prueba de Tukey $p \leq 0,01$ ) y fueron estadísticamente diferentes de los almacenados durante 14 y 21 días. Así mismo, los tubérculos almacenados durante 14 días en cámara fría presentaron la mayor presencia de micelio en el corte (Figura 1). Probablemente porque el tubérculo todavía está turgente, lo que favorece el desarrollo del micelio. Luego, conforme el tubérculo fue perdiendo humedad, se redujo la cantidad de micelio en el corte.

Marín (2001) informó que una vez que ocurre la maduración se inició el envejecimiento de los tejidos, seguido por la pérdida del contenido 
celular, oscurecimiento de los tejidos por oxidación, deformación debida a la pérdida de turgencia o jugos y pudriciones por hongos y bacterias.

La pérdida de peso en tubérculos es menor, debido a que el vapor de agua pasa del parénquima a la atmósfera exterior por medio de las lenticelas mientras que en las hortalizas de hoja y fruta se libera a través de las lenticelas, estomas y cutícula (Universidad de Tolima 2002).

La turgencia de las células se pierde porque el agua del protoplasma, se desplaza a través de sus membranas y por los espacios intracelulares, hasta la superficie del vegetal, para reponer la humedad que de allí ha sido retirada hacia el aire por la transpiración, al perder la turgencia (Universidad de Tolima 2002).

Con relación a los desinfectantes aplicados, todos los tratamientos se comportaron estadísticamente iguales, Tukey $(p \leq 0,05)$, en la variable presencia de micelio en el corte de los tubérculos (Figura 2).

\section{Estado de los brotes y yemas:}

Con respecto al análisis de varianza para las variables estado de los brotes y yemas de los tubérculos, no se presentaron diferencias significativas $(p \leq 0,05)$ en los tiempos de almacenamiento en cámara fría a $16{ }^{\circ} \mathrm{C}$ ni en los tratamientos desinfectantes aplicados. De acuerdo con lo observado en el ensayo, valorar los brotes y yemas como variable dentro de la apariencia externa, no es importante, debido a que éstos permanecieron en dormancia, proceso fisiológico que ocurre después de la cosecha, donde en este período, no hay evidencia o es casi imperceptible la presencia de ambos.

Ferguson (1977) citado por Rodríguez (2000), indicó que los tubérculos de ñame $D$. alata una vez cosechados, brotan después de
84 a 112 días de estar en reposo. Además, Pasam et al. (1982) citados por Rodríguez (2000) encontraron que el período de reposo es determinante genéticamente, más que el proceso de la madurez del tubérculo.

Cabe indicar que el ñame blanco Diamantes 22 , es un material con períodos inactivos largos de latencia como lo cita Aguilar ${ }^{4}$ (2008) y FAO (1993), lo cual facilitó su manejo en esta etapa de poscosecha y no hubo ni brotes ni yemas durante el ensayo.

Así mismo, Rao y George (1990) citado por Rodríguez (2000) prolongaron el reposo de los tubérculos de ñame $D$. alata por más de cinco meses, almacenándolos a $20{ }^{\circ} \mathrm{C}$, lo que evidencia que las bajas temperaturas reducen la tasa de actividad metabólica y, por ende, retrasan los cambios que conducen a la ruptura del reposo. No obstante, no deberían almacenarse ñames a temperaturas inferiores a los $15,00{ }^{\circ} \mathrm{C}$, porque por debajo de esta temperatura, se producen daños por excesivo enfriamiento.

\section{Presencia de micelio en daño mecánico:}

En lo que respecta a la variable presencia de micelio en daño mecánico, se detectaron diferencias altamente significativas $(p \leq$ 0,01 ) en el tiempo de almacenamiento $y$ desinfectantes aplicados a los tubérculos de ñame; adicionalmente, se encontraron diferencias significativas $(p \leq 0,05)$ en la interacción tiempo de almacenamiento por desinfectantes aplicados.

De acuerdo con la prueba de Tukey $(p \leq 0,05)$, todas las interacciones de desinfectantes aplicados por tiempo de almacenamiento fueron estadísticamente iguales y obtuvieron la menor presencia de micelio en daño mecánico, con excepción del Bacsan 5,00 mg/ I con 21 días de almacenamiento, el cual fue diferente al resto de las interacciones y obtuvo la mayor presencia de micelio sobre el daño mecánico de los tubérculos de ñame Diamantes 22. Se

\footnotetext{
${ }^{4}$ Aguilar, E. 2008. Período de latencia de los tubérculos de ñame. Comunicación personal. INTA. Guápiles, Estación Experimental Los Diamantes. Teléfono: (506) 2710-7851. Correo electrónico: eaguilar@inta.go.cr
} 
podría pensar que la dosis de Bacsan 5,00 $\mathrm{mg} / \mathrm{I}$ que se usó no funcionó, por lo que no redujo la cantidad de micelio presente en el daño mecánico de tubérculos.

\section{B.1. Incidencia de enfermedades:}

Para la variable incidencia de enfermedades hubo diferencias significativas en el tiempo de almacenamiento y diferencias altamente significativas para los desinfectantes aplicados y para la interacción de tiempo de almacenamiento por desinfectantes aplicados.

Según prueba de Tukey, todos los tratamientos fueron significativamente iguales con excepción del tratamiento Bacsan $5,00 \mathrm{mg} / \mathrm{I}$ durante 21 y 28 días de almacenamiento en cámara fría a $16^{\circ} \mathrm{C}$. El efecto significativo de los tratamientos y de la interacción tiempo de almacenamiento por desinfectantes aplicados, se debió fundamentalmente al tratamiento con Bacsan 5,00 mg/ I; probablemente por la concentración que se empleó.

\section{B.2. Número de lesiones:}

El análisis de varianza reflejó diferencias no significativas en el tiempo de almacenamiento, en la interacción del tiempo de almacenamiento por desinfectantes aplicados a los tubérculos, mientras que sí hubo diferencias altamente significativas $(p \leq 0,01)$ para los desinfectantes aplicados. De nuevo cabe indicar que el efecto significativo de los tratamientos desinfectantes se debió principalmente al tratamiento con Bacsan 5,00 mg/ I (prueba de Tukey). Por lo tanto, se podría pensar que la dosis empleada del desinfectante no fue la más adecuada para reducir la presencia de enfermedades poscosecha.

Segunda evaluación. Siete días después de permanecer a temperatura ambiente.

\section{A. Apariencia Externa:}

\section{Apariencia del Corte (corte de unión con la planta):}

De acuerdo con el análisis de varianza para la variable apariencia del corte de los tubérculos, se encontraron diferencias estadísticas $(p \leq$ 0,01 ) en el tiempo de almacenamiento, en los tratamientos desinfectantes y en la interacción entre el tiempo de almacenamiento por desinfectantes aplicados, por lo tanto, existió dependencia entre ambos factores.

Cabe indicar que los tratamientos que presentaron la mejor apariencia del corte (prueba de Tuckey $p \leq 0,01$ ) fueron los tubérculos tratados con desinfectantes y almacenados a 7, 14, 21 y 28 días, con excepción del Bacsan a 5,00 mg/ I durante 7, 14 y 21 días de almacenamiento, tratamientos que presentaron el mayor deterioro del corte y fueron estadísticamente inferiores a los demás.

\section{Presencia de micelio en el corte (corte de unión con la planta):}

Se presentaron diferencias significativas ( $p$ $\leq 0,05$ ) en el tiempo de almacenamiento y para los desinfectantes aplicados, en tanto que, la interacción de los factores no mostró diferencias significativas.

Con relación a los desinfectantes aplicados, todos se comportaron estadísticamente iguales con excepción del Bacsan $5 \mathrm{mg} / \mathrm{I}$ que presentó la mayor presencia de micelio en el corte de los tubérculos y fue estadísticamente inferior comparado con el Hipoclorito de sodio, que obtuvo el menor valor para esta variable (Figura 3). Pirovani et al. (2006) informaron que el hipoclorito de sodio es recomendado para desinfección de cortes, y en este caso en particular es el desinfectante que mejor funciona en bajar la presencia de hongos. 


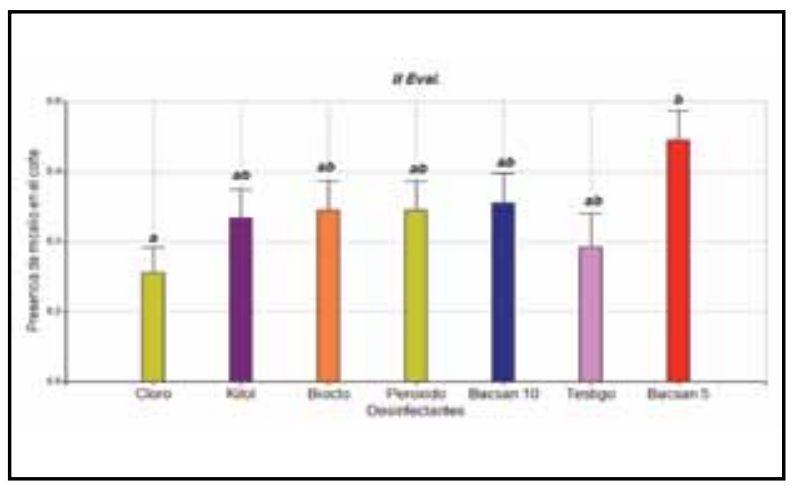

Figura 3. Presencia de micelio en el corte de los tubérculos de ñame Diamantes 22, tratados con diferentes desinfectantes y almacenados en cámara fría (16 $\left.{ }^{\circ} \mathrm{C}\right)$ y 7 días a temperatura ambiente (simulando anaquel) San José, Costa Rica. 2007.

Vero et al. (2006) y SENATI (s.f.) mencionaron que el cloro es capaz de entrar en contacto con suciedad y gérmenes, y logra romper en pequeñas unidades la cadena de moléculas matando bacterias y mohos, luego libera oxígeno activo que ataca y descompone las proteínas destruyendo los microorganismos.

El uso de desinfectantes tales como el cloro en los cortes de hortalizas y en el agua de refrigeración puede ayudar a reducir los riesgos asociados con la internalización de los patógenos en el producto agrícola (University of Maryland 2002)

En la Figura 4, se observa que los tubérculos almacenados durante 7 y 28 días en cámara fría, obtuvieron menor presencia de micelio en el corte, que aquéllos almacenados durante 21 días. Esto pudo deberse a que a los 7 días, los tubérculos estaban más protegidos por los desinfectantes aplicados, debido a que la mayoría actúan por contacto.

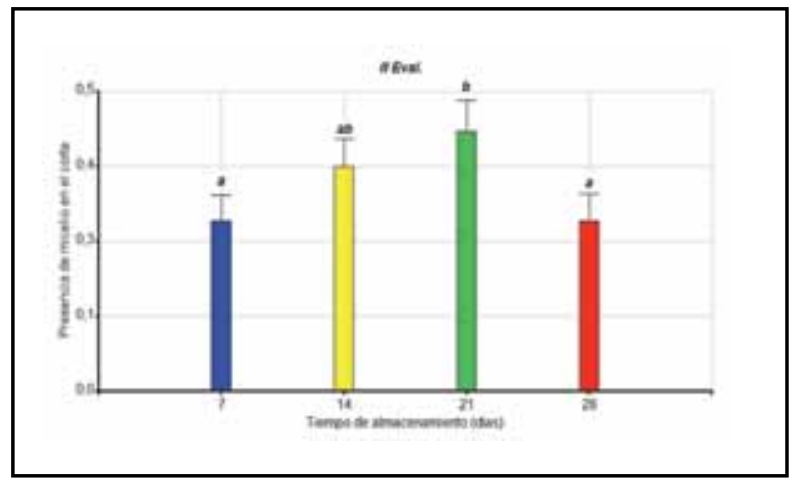

Figura 4. Presencia de micelio en el corte de tubérculos de ñame Diamantes 22 almacenados en cámara fría (16 $\left.{ }^{\circ} \mathrm{C}\right)$ y 7 días a temperatura ambiente (simulando anaquel). San José, Costa Rica. 2007.

Por otro lado, tubérculos almacenados durante 28 días en la cámara fría, presentaron pérdidas de agua por deshidratación de los tubérculos, lo que favoreció la presencia de mohos (hongos poscosecha) en el corte. Muchos de estos patógenos (patógenos de lesiones) invaden el tubérculo a través de las lesiones causadas por nematodos o por daños físicos, tales como cortes y rozaduras. Las lesiones, raspaduras, magulladuras o cortes son entradas propicias para el ataque de patógenos y presencia de pudriciones durante el almacenamiento (FAO 1993)

\section{Estado de los brotes y yemas:}

No se presentaron diferencias significativas $(p \leq 0,01)$ en los tiempos de almacenamiento en cámara fría a $16{ }^{\circ} \mathrm{C}$, seguido por siete días a temperatura ambiente (simulación en anaquel), así como tampoco para los tratamientos desinfectantes aplicados para el estado de brotes y yemas.

\section{Presencia de micelio en daño mecánico:}

Se presentaron diferencias estadísticas $(p \leq$ 0,01 ) en el tiempo de almacenamiento y en la interacción de los factores ( $p \leq 0,05)$, lo que denota que existió dependencia entre los factores desinfectantes aplicados y tiempos 
de almacenamiento. No hubo diferencias significativas para los diferentes desinfectantes aplicados.

Con excepción del tratamiento Bacsan 5,00 $\mathrm{mg} / \mathrm{I}$ a los 21 días de almacenamiento en cámara fría y 7 días a temperatura ambiente (7 días anaquel), todos los tratamientos fueron estadísticamente iguales y tuvieron menor presencia de micelio en el daño mecánico. Boyette et al. citados por Ávila (1993) encontraron que la reducción en daños mecánicos en la banda de clasificación y empaque, reduce directamente la presencia del producto afectado porque muchos organismos entran a frutas $y$ vegetales a través de heridas.

\section{B.1.Incidencia de enfermedades:}

No hubo efecto en el tiempo de almacenamiento ni en la interacción de tiempo de almacenamiento por desinfectantes aplicados, en tanto que sí se presentaron diferencias significativas ( $p \leq 0,01)$ entre los desinfectantes aplicados. Cabe indicar que el efecto significativo de los desinfectantes se debió precisamente al desinfectante Bacsan $5,00 \mathrm{mg} / \mathrm{l}$, con el que ocurrió la mayor incidencia de tubérculos de ñame con enfermedades. Asimismo, los demás desinfectantes aplicados fueron estadísticamente iguales al testigo (Figura 5). La incidencia de enfermedades fue muy baja en este ensayo, lo cual pudo deberse a que los tubérculos de exportación empleados fueron bien seleccionados por el personal de la empacadora. Esto coincide con lo informado por Boyette et al. (1993) citados por Ávila (1997) quienes señalaron que al incrementar la eficiencia y mejorar el manipuleo de frutas y vegetales frescos en sitios de empaque, se reducen las pérdidas poscosecha.

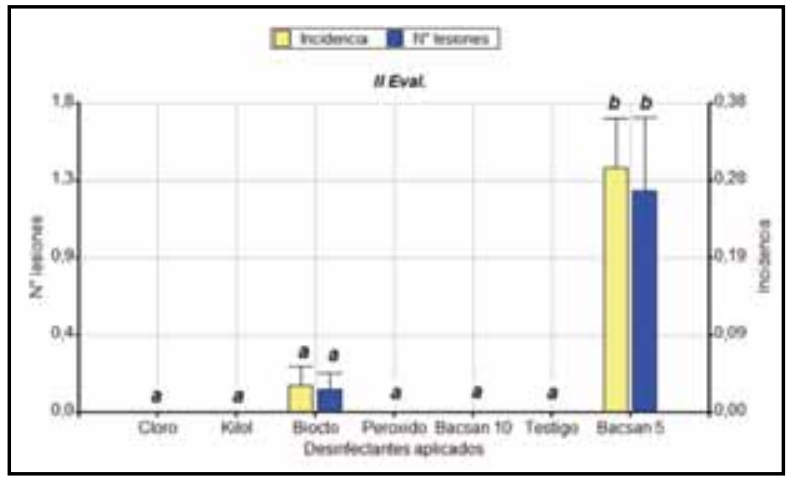

Figura 5. Determinar la incidencia y número de lesiones de enfermedades presentes en los tubérculos de ñame Diamantes 22, con diferentes tratamientos desinfectantes y almacenados en cámara fría $\left(16^{\circ} \mathrm{C}\right)$ y siete días a temperatura ambiente. San José, Costa Rica. 2007.

La presencia de enfermedades en poscosecha en la mayoría de los casos depende de la calidad y tipo de manejo que se le da al producto en la cosecha, en el transporte, en el lavado de los tubérculos y en la buena selección del producto de alta calidad en la empacadora.

Castro y Saborío (2004) informaron que el uso de Buenas Prácticas de Manejo de hortalizas y frutas frescas suministradas durante el desarrollo del cultivo, precosecha, cosecha, selección, almacenaje, transporte e higiene del trabajador, previnieron la ocurrencia de errores y se evitaron daños mayores.

Una manera de reducir la pérdidas poscosecha de ñame consiste en recolectar el producto cuando no esté lloviendo, colocar los tubérculos bajo sombra, trasladar el producto inmediatamente a la empacadora, debidamente seleccionado, sin podredumbres - lesiones físicas como raspaduras, heridas, magulladuras o daños provocados por nematodos; además, seleccionarlo adecuadamente en la empacadora, lavarlo con agua limpia, de ser posible con algún tratamiento poscosecha, secar y curar por un período de 4 a 7 días (Castro y Saborío 2004; FAO 1993; FAO s.f.) 


\section{B.2. Número de lesiones en los tubérculos:}

No se presentaron diferencias estadísticas en el tiempo de almacenamiento ni para la interacción de los factores, no obstante, sí las hubo $(p \leq 0,05)$ entre los desinfectantes aplicados para la variable. Además, debe aclararse que estas diferencias se debieron nuevamente al desinfectante Bacsan $5,00 \mathrm{mg} / \mathrm{l}$, el cual presentó el mayor número de lesiones en los tubérculos de ñame a diferencia de los demás tratamientos (Figura 5).

Boyette et al. (1993) citado por Ávila (1997) mencionaron que las pérdidas poscosecha pueden ser causadas por cualquier hongo o bacteria, aunque los hongos son encontrados más frecuentemente que bacterias tanto en frutas como vegetales. La presencia de lesiones estuvo asociada en este caso a hongos y no aparecieron bacterias afectando la calidad de los tubérculos de exportación en este ensayo.

La aplicación del Bacsan 5,00 mg/ I pudo ocasionar una enfermedad iatrogénica (efectos negativos provocados por cualquier producto aplicado en sobredosis al cultivo en cualquier estado fisiológico), al no emplearse la cantidad óptima y eficaz del desinfectante, lo que pudo ocasionar un efecto detrimental con su aplicación. Además, se pudo potenciar el daño por microorganismos presentes en los tubérculos y se desencadenó una reacción adversa al aplicar el desinfectante. (Wuani 2001; Wikipedia 2008)

Tercera Evaluación. Catorce días después de permanecer a temperatura ambiente

\section{Apariencia Externa}

\section{Apariencia del Corte (corte de unión con la planta):}

No se evidenciaron diferencias estadísticas en el tiempo de almacenamiento de los tubérculos, ni para la interacción tiempo de almacenamiento por desinfectantes aplicados, para la variable apariencia del corte; en tanto que si se encontraron diferencias significativas $(p \leq 0,01)$ para los desinfectantes aplicados, no obstante, las diferencias que existen entre los desinfectantes aplicados se debieron exclusivamente al desinfectante Bacsan 5,00 $\mathrm{mg} / \mathrm{l}$, el cual presentó el mayor deterioro del corte y fue inferior a los demás tratamientos evaluados, incluyendo al testigo (Figura 6).

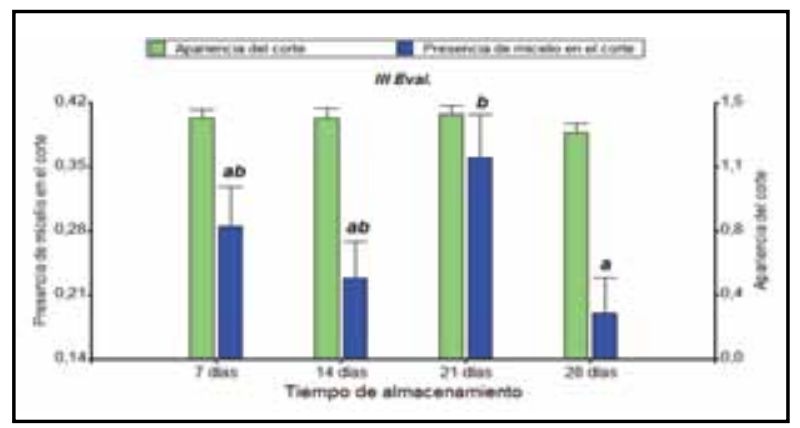

Figura 6. Apariencia del corte y presencia de micelio en el corte (unión con la planta) de los tubérculos de ñame Diamantes 22, después del almacenamiento en cámara fría a $16{ }^{\circ} \mathrm{C}$ y 14 días a temperatura ambiente (simulando anaquel). San José, Costa Rica. 2007.

Según Castro y Saborío (2004); Carmona (2004); Umaña y Sáenz (2004) lo anterior expuesto pudo deberse al buen manejo de tubérculos en el campo, a la excelente selección de los mismos, al adecuado manejo y proceso de limpieza en la empacadora, lo que denota que al trabajar con tubérculos de buena calidad y bien seleccionados, es posible que no requieran la aplicación de desinfectantes.

Sin embargo, considerando la inocuidad de alimentos, se recomendó el uso de algún desinfectante que reduzca la infección de microorganismos, que evitan dañar la salud humana, como lo mencionaron (Castro y Saborío 2004; Umaña y Sáenz 2004).

\section{Presencia de micelio en el corte (corte de unión con la planta):}

Se presentaron diferencias estadísticas ( $p \leq$ 0,05 ) en el tiempo de almacenamiento y los desinfectantes aplicados, en tanto que no hubo diferencias significativas para la interacción 
tiempo de almacenamiento por desinfectantes aplicados para la variable presencia de micelio en el corte. Respecto al factor tiempo de almacenamiento (prueba de Tukey $p \leq 0,05$ ) los tubérculos que permanecieron por 28 días en cámara fría y 14 días a temperatura ambiente, tuvieron menos micelio en el corte y fueron estadísticamente similares a los que presentaron 7 y 14 días en almacenamiento dentro de la cámara fría.

Lo anterior expuesto, pudo deberse a que a los 28 días hubo más deshidratación y no favoreció las condiciones para el desarrollo de micelio de hongos en el corte. En contraposición a lo anterior, los tubérculos almacenados durante 21 días, presentaron la mayor presencia de micelio y fueron estadísticamente inferiores a los demás (Figura 6). Esto pudo deberse a que a 21 días de almacenamiento, la acción de los desinfectantes fue inefectiva en el desarrollo del micelio en el corte, a consecuencia del tiempo que se tenía de la aplicación de los desinfectantes. Se perdió turgencia al desplazarse el agua dentro de células del protoplasma y se dirigió hasta la superficie vegetal para reponer la humedad perdida por la transpiración (Universidad de Tolima 2002).

Los desinfectantes aplicados fueron estadísticamente similares al testigo (prueba de Tukey $p \leq 0,05)$ y presentaron la menor presencia de micelio en el corte, a diferencia del tratamiento Bacsan $5 \mathrm{mg} / \mathrm{I}$, que fue estadísticamente inferior a los demás por obtener la mayor presencia de micelio en el corte (Figura 7). La selección adecuada de los tubérculos a exportar favoreció minimizar las pérdidas poscosecha como se encontró en estos resultados. Umaña y Sáenz 2004, mencionaron que tratamientos poscosecha aplicados a tejidos vegetales, pudieron disminuir las poblaciones de microorganismos que pueden afectar la calidad del producto agrícola o la salud de los consumidores.

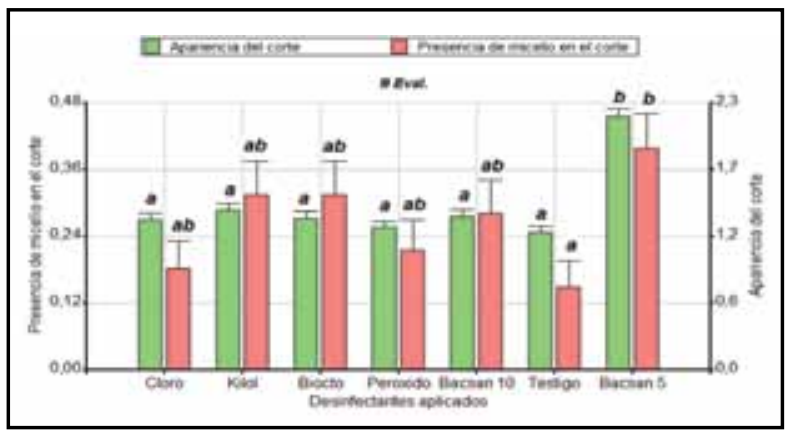

Figura 7. Apariencia del corte y presencia de micelioenelcortedetubérculos deñame Diamantes 22, después del tratamiento con diferentes desinfectantes luego del almacenamiento en cámara fría a 16 ${ }^{\circ} \mathrm{C}$ y 14 días a temperatura ambiente (simulando anaquel) San José, Costa Rica. 2007.

\section{Estado de los brotes y yemas:}

No hubo diferencias estadísticas en los tiempos de almacenamiento en cámara fría a $16{ }^{\circ} \mathrm{C}$, ni con los tratamientos desinfectantes aplicados, debido al estado de dormancia en que permanecieron durante el estudio, según Rodríguez (2000).

\section{Presencia de micelio en daño mecánico:}

No se presentaron diferencias significativas en el tiempo de almacenamiento, desinfectantes aplicados, ni en la interacción tiempo de almacenamiento por desinfectantes aplicados, para la presencia de micelio en daño mecánico de los tubérculos. Asimismo, tubérculos tratados con desinfectantes y dejados a 7 y 14 días en anaquel, no presentaron diferencias significativas, en tanto que a 0 días anaquel, hubo diferencias significativas debidas al Bacsan 5 mg/ I y 21 días en cámara fría.

\section{B.1. Incidencia de enfermedades:}

En lo que respecta a la variable incidencia de enfermedades, no hubo diferencias significativaseneltiempo dealmacenamientoni en la interacción de tiempo de almacenamiento por desinfectantes aplicados. Sin embargo, sí se presentaron diferencias significativas 
( $p \leq 0,05)$ entre los desinfectantes analizados. Merece indicar, que el efecto significativo de los desinfectantes se debió exclusivamente al desinfectante Bacsan $5 \mathrm{mg} / \mathrm{I}$, el cual fue estadísticamente diferente e inferior a los demás tratamientos (Figura 8).

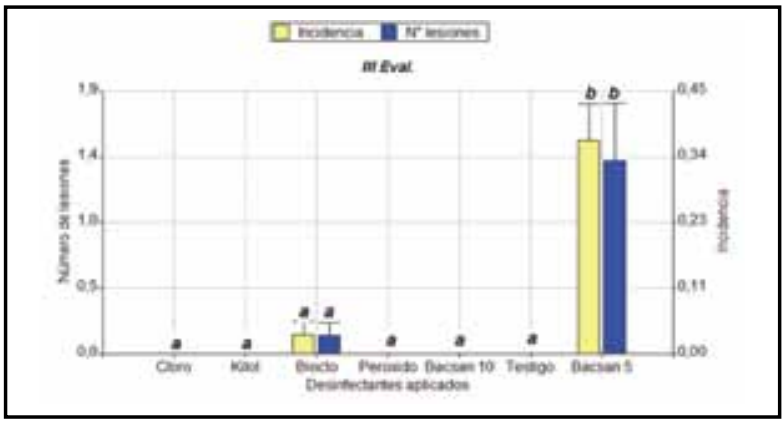

Figura 8. Incidencia y número de lesiones de enfermedades presentes en tubérculos de ñame Diamantes 22, según, desinfectantes aplicados y después de permanecer en almacenamiento a $16{ }^{\circ} \mathrm{C}$ y catorce días a temperatura ambiente (simulando un anaquel) San José, Costa Rica. 2007.

La incidencia de las enfermedades en los tubérculos de ñame Diamantes 22 fue muy bajo; la mayoría de los tubérculos tratados no presentaron enfermedades. Esto pudo deberse a los esfuerzos que se hicieron en la empacadora para reducir daños que pudieron causar pérdidas poscosecha y aparentemente fue exitoso para reducir la incidencia de enfermedades en raíces y tubérculos (Boyette et al. 1993 citado por Ávila, 1997).

\section{B.2. Número de lesiones en los tubérculos:}

No se presentaron diferencias significativas en el tiempo de almacenamiento ni para la interacción de tiempo de almacenamiento por desinfectantes aplicados. No obstante, sí se presentaron diferencias significativas $(p \leq$ 0,01 ) entre los desinfectantes aplicados. Sin embargo, estas diferencias fueron debidas al desinfectante Bacsan $5 \mathrm{mg} / \mathrm{I}$, que evidenció el mayor número de lesiones presentes en los tubérculos de ñame. Con excepción del desinfectante Bacsan $5 \mathrm{mg} / \mathrm{I}$, los tubérculos aplicados con el resto de los desinfectantes evaluados, fueron estadísticamente iguales al testigo (Figura 8) Lo anterior expuesto coincide con Boyette et al. (1993) citado por Ávila (1997) quien opina que los tubérculos de exportación empleados para el ensayo hayan sido seleccionados eficientemente por el personal de la empacadora.

\section{Identificación de microorganismos presentes en tubérculos de ñame variedad Diamantes 22}

De acuerdo con los tratamientos desinfectantes evaluados, se encontró que al analizar los cortes, daños mecánicos y lesiones en los tubérculos de ñame Diamantes 22, los microorganismos encontrados durante las evaluaciones fueron los hongos, Penicillium spp. con mayor frecuencia $(85,70 \%)$ y Aspergillus spp. en menor frecuencia $(7,14$ $\%)$, Cuadro 1. Cabe indicar que en este ensayo observó la presencia de bacterias que afectaran la sanidad de los tubérculos, Cuadro 1. 
López Marín. Efecto de Diferentes Tiempos de Almacenamiento, Desinfectantes y Extractos Vegetales en Poscosecha sobre Tubérculos de Ñame Blanco (Dioscorea Alata L.) de Exportación

Cuadro 1. Microorganismos encontrados en diferentes tratamientos en tubérculos de ñame con desinfectantes aplicados en poscosecha. San José, Costa Rica. 20071

\begin{tabular}{|c|c|c|c|c|}
\hline Tratamiento & 7DCF $^{*}+$ DTA $^{* \star}$ & 14 DCF+7 DTA & 21 DCF+7DTA & 28DCF+7DTA \\
\hline $\begin{array}{l}\text { Hipocloritode } \\
\text { sodio(NaOCl) }\end{array}$ & Aspergillus sp. & Aspergillus sp. & Penicillium sp. & Penicillium sp. \\
\hline Kilol & Penicillium sp. & Penicillium sp. & Negativo & Penicillium sp. \\
\hline Biocto & Penicillium sp. & Penicillium sp. & Penicillium sp. & Penicillium sp. \\
\hline $\begin{array}{c}\text { Peróxido de } \\
\text { hidrógeno }\left(\mathrm{H}_{2} \mathrm{O}_{2}\right)\end{array}$ & Penicillium sp. & Penicillium sp. & Penicillium sp. & Negativo \\
\hline $\begin{array}{l}\text { Citrato de plata } \\
\text { (Bacsan } 10 \text { ppm) }\end{array}$ & Penicillium sp. & Penicillium sp. & Penicillium sp. & Penicillium sp. \\
\hline Testigo (agua) & Penicillium sp. & Penicillium sp. & Penicillium sp. & Penicillium sp. \\
\hline $\begin{array}{l}\text { Citrato de plata } \\
\text { (Bacsan } 5 \text { ppm) }\end{array}$ & Penicillium sp. & Penicillium sp. & Penicillium sp. & Penicillium sp. \\
\hline
\end{tabular}

Los tubérculos aplicados con hipoclorito de sodio, presentaron dos hongos: Aspergillus spp. y Penicillium spp.; mientras que en el resto de los tratamientos utilizados, se presentó Penicillium spp.

Aspergillus spp. y Penicillium spp. aparecieron frecuentemente en tubérculos de ñame Diamantes 22 evaluados en poscosecha, lo que coincide con lo informado por Amusa et al. (2003) quienes mencionaron que estos agentes causan enfermedades en ñame, además, están asociados con el almacenamiento y el período de mercadeo. Umaña y Sáenz (2004) citan la presencia de Penicillium spp., Aspergillus spp. y algunas especies del género Fusarium spp. como hongos que ocasionan daños poscosecha en tejidos vegetales.

Es importante indicar que la presencia de Penicillium spp. se repitió en todas las evaluaciones realizadas.

\section{CONCLUSIONES}

La apariencia del corte de los tubérculos evaluados a los 7, 14, 21 y 28 días de permanencia en cámara fría y 0 días en anaquel presentaron diferencias estadísticas, sin embargo, para 7 y 14 días anaquel sólo se presentaron diferencias significativas para el factor desinfectante aplicado y se debieron al tratamiento Bacsan $5,00 \mathrm{mg} / \mathrm{l}$, y, tubérculos almacenados por 7 días en cámara fría y 0 días anaquel, obtuvieron una mejor apariencia en el corte (unión a la planta).

A 7 y 14 días anaquel todos los tratamientos fueron estadísticamente similares con excepción del Bacsan 5,00 mg/ I que obtuvo el mayor deterioro en la apariencia del corte a 0,7 y 14 días anaquel.

Tubérculos almacenados a 7 días en cámara fría y 0 días anaquel tuvieron la menor presencia de micelio en el corte.

El desinfectante hipoclorito de sodio obtuvo menor presencia de micelio en el corte de tubérculos durante el almacenamiento a 7 días anaquel.

A 0 y 14 días anaquel todos los desinfectantes fueron similares al Testigo en la presencia de micelio en el corte con excepción del Bacsan 5,00 mg/ I que obtuvo el mayor valor encontrado. 
No hubo evidencia de brotes y yemas de los tubérculos almacenados durante todo el ensayo por la duración de los mismos (42 días).

Tubérculos tratados con Bacsan 5,00 mg/ I a 21 días en cámara fría y 0 días anaquel obtuvieron mayor presencia de micelio sobre el daño mecánico.

Tubérculos almacenados a 21 y 28 días en cámara fría y 0 días anaquel presentaron mayor incidencia de enfermedades comparado con el resto de los tratamientos.

Los tubérculos tratados con Bacsan $5,00 \mathrm{mg} /$ I a 7 y 14 días anaquel presentaron mayor incidencia de enfermedades con respecto a los demás tratamientos evaluados.

A 0, 7 y 14 días anaquel, Bacsan $5 \mathrm{mg} / \mathrm{l}$ evidenció el mayor número de lesiones presentes en los tubérculos de ñame y fue diferente a todos los demás desinfectantes evaluados.

Los hongos presentes en el corte, daño mecánico y lesiones en tubérculos de ñame Diamantes 22 fueron Penicillium spp. con 85,70 \% y Aspergillus spp con 7,14\%.

No se presentaron enfermedades bacteriales en los tubérculos analizados.

\section{RECOMENDACIONES}

Seleccionar tubérculos de ñame de exportación de primera calidad desde campo hasta empaque, reducen problemas fitosanitarios en poscosecha.

Se sugiere hacer tratamiento por inmersión con hipoclorito de sodio, si bien es cierto, no hubo diferencias significativas entre los desinfectantes y el testigo, este tratamiento puede minimizar problemas de índole fitopatológico, minimiza el porcentaje de tubérculos enfermos, y reduce el riesgo de contaminación de microorganismos que afectan la salud humana y es el producto con menor costo de adquisición y de fácil acceso.
Evaluar los desinfectantes en ñame blanco en varias empacadoras de exportación, puesto que el inóculo de enfermedades depende del lote, las condiciones climáticas, la región y de la clasificación de los tubérculos de ñame que se hace en las empacadoras de exportación, además de valorar el uso de diferentes concentraciones de los mismos.

Considerar tratamientos alternativos como controladores biológicos $u$ otros extractos vegetales a los ya empleados en este ensayo. Okigbo (2004); Okigbo y Ogbonaya (2006) mencionan el uso de Trichoderma viride y el uso de extractos vegetales extraído de Ocimum gratissimum para el control de enfermedades poscosecha en ñame en Nigeria.

Excluir las variables apariencia de brotes y yemas para los tubérculos de Diamantes 22 dado que Dioscorea alata tiene un período de dormancia de cuatro a seis meses y no es necesario emplearlas como variables que puedan afectar la apariencia externa de los tubérculos.

Hacer estudios con desinfectantes en condiciones de alta presión de inóculo de enfermedades poscosecha, para comprobar la eficiencia de los diferentes desinfectantes empleados.

\section{LITERATURA CITADA}

Adelusi; A.A., Lawanson, A.O. 1987. Disease induced changes in carotenoid content of edible yam (Dioscorea spp.) infected by Botryodiplodia theobromae and Aspergillus niger. Mycopathología 98: 49-58. Consultado 22 agosto 2007. Disponible en www.springerlink.com/ index/P16123527234K3 82.pdf -

Amusa, N.A.; Adegbite, A.A.; Muhammed, S.; Baiyewu, R.A. 2003. Yam diseases and its management in Nigeria. African Journal of Biotechnology. 2(12): 497502. Consultado 22 agosto 2007. Disponible en www.academic journals org/AJB/abstracts/abstracts2003/ Decemberabstracts2003/Amusa\%20 et\%20al.htm 18k. 
Avila, G. 1997. Manejo poscosecha de hortalizas bulbosas. Condiciones para el secado artificial del ajo. Avances de Horticultura. 2(1). Edición on line. Consultado 22 agosto 2007. Disponible en www.horticulturaar.com. ar/ php?archivo $=1997 * 97$-avila.

Carmona, G. 2004. Tratamientos Poscosecha. In Sistemas de Poscosecha y cumplimiento con requisitos de calidad e inocuidad de alimentos: Un enfoque práctico. ACCS. San José, Costa Rica. p. 123-132.

Castro, M.V.; Saborío, D. 2004. Tratamientos Poscosecha. In Sistemas de Poscosecha y cumplimiento con requisitos de calidad e inocuidad de alimentos: Un enfoque práctico. ACCS. San José, Costa Rica. p. 107-116.

CNP (Consejo Nacional de Producción). 2001. Calidad de las aguas para uso agrícola: Guía Técnica Poscosecha $\mathrm{N}^{\circ}$ 2. San José, Costa Rica. CNP 7-9 p. Consultado 27 setiembre. 2007. Disponible en http://www.mercanet. cnp.go. cr.

CNP (Consejo Nacional de Producción). 2010. Exportaciones por país, año, volumen y valor - Periodo 1999-2010. Sistema de Información e Inteligencia de Mercado. Boletín 1. CNP. San José, Costa Rica. Consultado 22 agosto 2007. Disponible en www.cnp.go.cr/ phpmysql_/admin/KTML/uploads/files/ boletines/_ame-1-07.pdf -

Coursey, D.G. 1967. Yam storage 1: A review of storage practices and information on storage losses. Journal of Stored Products Research 2: 229-244. Consultado 27 setiembre 2007. Disponible en https://tspace.library. Uto ronto.ca/bitstream/1807/1909/1/ jb03098.pdf.

FAO (Organización para la Agricultura y la Alimentación). 1993. Prevención de pérdidas de alimentos poscosecha; hortalizas, raíces y tubérculos. FAO.
Roma, Italia. Serie № 17.183 p.

FAO (Organización para la Agricultura y la Alimentación). s.f. Manual para el mejoramiento del manejo poscosecha de frutas y hortalizas. Consultado 20 julio 2008. Disponible en www.fao.org/ docrep/x5056S03.htm-45k.

Kornoski, M.V.; Agostini, J.P., Acuña, L.E. 2006. Detección de bacterias causantes de cancrosis desde frutas asintomáticas a campo y en galpón en empaque. $\mathrm{N}{ }^{\circ} 31$. INTA. Montecarlo, Misiones. Consultado 27 setiembre 2007. Disponible en www.inta.gov.ar/ montecarlo.

Marín, F. 2001. La Maduración de los Productos Hortícolas. Consejo Nacional de la Producción (CNP): Guía Técnica Poscosecha $n^{\circ} 4$. Consultado 18 julio 2008. Disponible en http:/ www.mercanet.cnp.go.cr/Calidad/ Poscosecha/Guía s_Técnicas/ documentospdf/M.

Okigbo, 2004. A rewiew of biological control methods for post harvest yams (Dioscorea spp) in storage in South Eastern Nigeria. Arabia State, Nigeria. KMITL Science Journal. 4(1): 207215. Consultado 27 setiembre. 2007. Disponible en www.kmitl.ac.th/ejkmitl/ vol4no1/Biological control.pdf -

Okigbo, R.; Ogbonnaya, U. 2006. Antifungal effects of two tropical plant leaf extracts (Ocimum gratissimum and Aframomum melegueta) on postharvest yam (Dioscorea spp.) root. African Journal of Biotechnology 5(9): 727-731. Consultado 27 setiembre 2007. Disponible en www.bioline.org. br/request? jb06130 - 27k -

Pirovani, M.E.; Guemes, D.R.; Piagentini, A.M. 2006. Lavado desinfección con soluciones cloradas: una etapa para mejorar la calidad microbiológica de vegetales de hoja frescos cortados. Instituto de Tecnología de Alimentos. Brazil. Consultado 20 julio 2008. 
Disponible en http:/www.ciad.mx/ dtaov/XI_22CYTED/images/files_pdf/ Brasil/maria.pdf-Windows

Rodríguez, W. 2000. Botánica, domesticación y fisiología del cultivo de ñame (Dioscorea alata). Agronomía Mesoamericana. 11(2): 133-152. Consultado 20 julio 2008. Disponible en redalyc.uaemex.mx/src/inicio/ ArtPdfRed.jsp? 43711221.

Saborío, D. 2003. Algunas normas de calidad en raíces y tubérculos tropicales de exportación de Costa Rica. Agronomía Costarricense 27(1): 49-61. Consul- tado 20 julio 2008. Disponible en redalyc.uaemex.mx/ redalyc/html/436/.../436 27105.html.

Segura, A. 2000. Evaluación de algunos parámetrosdecalidadenlasprincipales raíces y tubérculos exportados por Costa Rica. Universidad de Costa Rica. Tesis de Grado para optar por el título de Licenciatura en Ingeniería Agronómica. San José, Costa Rica. 79 p.

SENATI (Servicio Nacional de Adiestramiento en Trabajo Industrial). s.f. Limpieza y desinfección. Consultado 20 julio 2008. Disponible en http:/inranet.Sen ati.edu.peDox/lpace/DescargasWeb/ Panaderia_y Pasteleria/ BPM.

Umaña, G.; Sáenz, M. V. 2004. Tratamientos Poscosecha. In Sistemas de Poscosecha y cumplimiento con requisitos de calidad e inocuidad de alimentos: Un enfoque práctico. ACCS. San José, Costa Rica. p. 134152.

Universidad de Tolima. 2002. Manejo y poscosecha y procesamiento de frutas y hortalizas. Colombia. Proyecto de Servicios Integrados para Jóvenes del Cañón del Combeina. Consultado 18 julio 2008. Disponible en http:/ut. edu. co/fif/proyectos/psijcc/docs/stalleres/ anejo_procesa_frutas_horta.doc
University of Maryland. 2002. Mejoramiento de la seguridad y calidad de frutas y hortalizas frescas: Manual de Formación para Instructores. Consultado 18 julio 2008. Disponible en http:/www.jifsan.umd.edu/PDFs/ GAPS_Español español.pdf-Windows Internet Explorer.

Vero, S.; Garat, F.; Wozniak, A.; Garmendia, G.; Alaniz, S.; de Aurrecoechea, I. 2006. Alternativas al tratamiento convencional en poscosecha de citrus. Consultado 20 julio 2008. Disponible en http:/www.pv.fagro.edu.ey//fitopa to/ publica/Conferencia 15.pdf-Windows

Wikipedia. 2008. latrogenia. Consultado 24 julio 2008. Disponible en: es.wikipedia. org/wiki/latrogenia - 51k -

Wuani, H. 2001. latrogenia. Medicina Interna, Educación Médica y Comunidad 17(2): 46-55. Consultado 24 julio 2008. Disponible en http://www.svmi. org.ve/ revistas/vol17n2/medint. pdf. 